\title{
Modified peroral pyloromyotomy and placement of a covered stent for refractory gastric outlet obstruction following ingestion of sulfuric acid
}
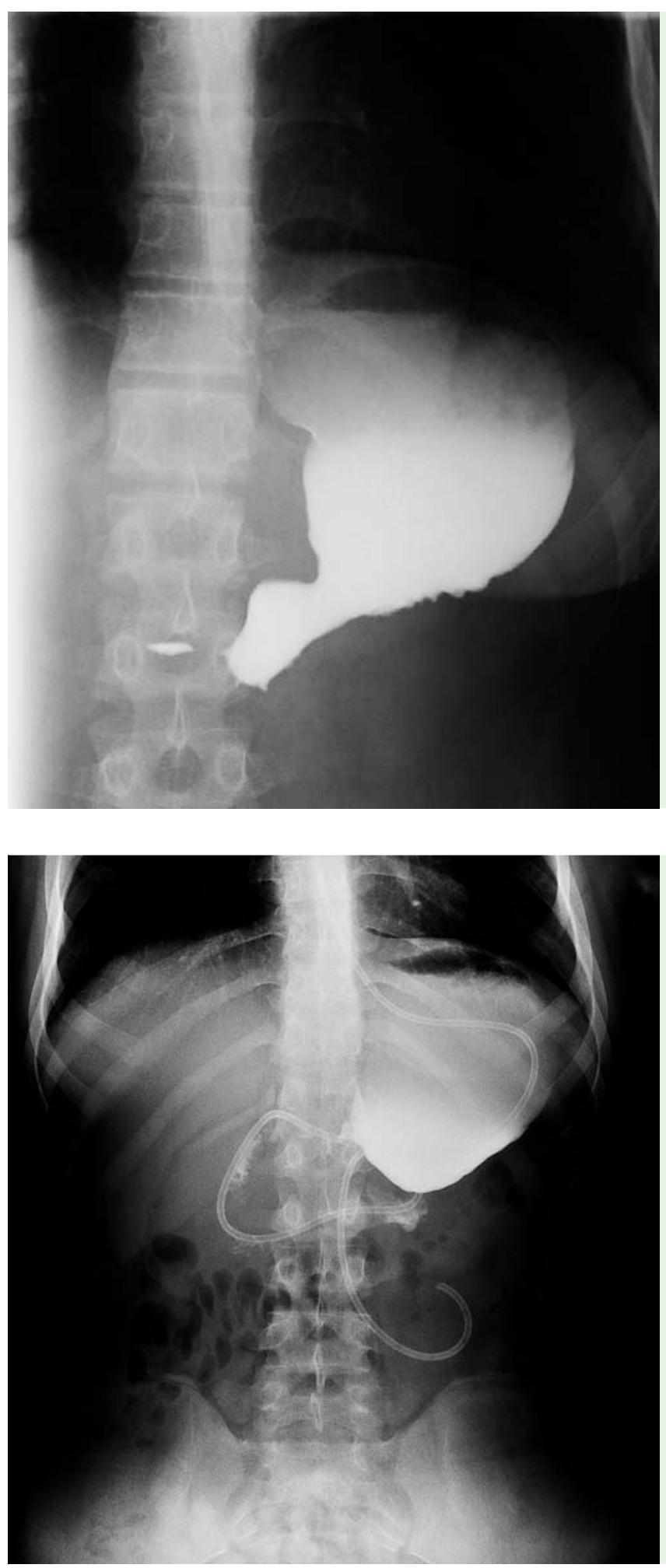

Fig. 1 Barium swallow revealed marked delay in passage of contrast through the pylorus.

Fig. 3 At 2 months after endoscopic balloon dilation, barium swallow showed recurrent pyloric narrowing.

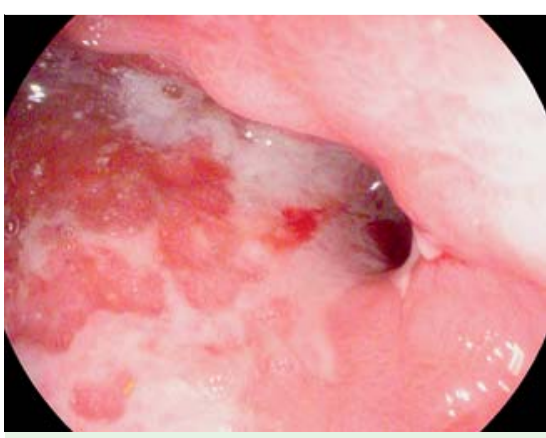

Fig. 2 Endoscopy showed antropyloric narrowing, and the scope could not be passed through the pylorus.

A 15-year-old boy accidentally ingested a mouthful of sulfuric acid $(160 \mathrm{~g} / \mathrm{L})$. He presented 20 days later with complaints of postprandial epigastric distress, repeated nonbilious vomiting, and marked weight loss (about $15 \mathrm{~kg}$ ). Barium swallow and endoscopy revealed antropyloric narrowing ( Fig. 1, $\bullet$ Fig. 2). Endoscopic balloon dilation was performed, and the symptoms were relieved. However, 2 months later the symptoms recurred, and barium swallow again showed pyloric narrowing ( $\bullet$ Fig.3).

Following approval by the Ethics Committee of Provincial Hospital Affiliated to Shandong University and in accordance with the Declaration of Helsinki for Medical Research involving Human Subjects, modified peroral pyloromyotomy and placement of a covered stent were performed with the patient under general anesthesia. Radial incisions were made from the antrum to the duodenal bulb, and the pyloromyotomy was performed using a HookKnife (KD-620LR, Olympus, Tokyo, Japan). An endoscopic transpyloric covered stent was then placed $(20 \times 100 \mathrm{~mm}$; Micro-Tech [Nanjing] Co., Ltd., Nanjing, China) ( $\bullet$ Video 1$)$.

Two weeks after the operation, stent migration was noted. The stent was retrieved and the patient was healthy with no problems after feeding. However, 3 months after the operation, he returned to the clinic with recurrent vomiting. The 


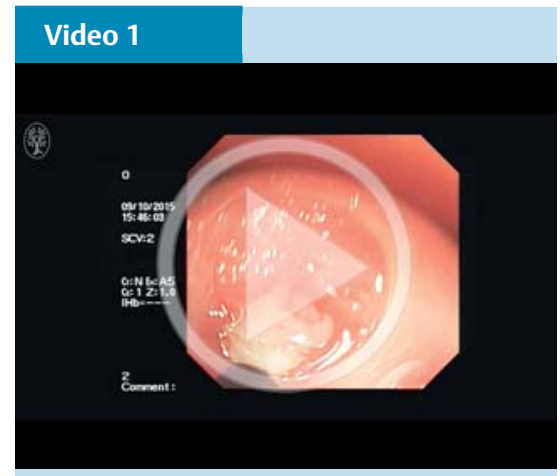

Modified peroral pyloromyotomy and placement of a covered stent for the treatment of refractory gastric outlet obstruction following ingestion of sulfuric acid. ed. The stent remained in place for 3 weeks and was then removed. After another 3 months, the patient remained asymptomatic and was thriving ( $\bullet$ Fig.4).

Endoscopic pyloromyotomy has been used to improve gastric emptying in selected patients with diabetic-associated refractory gastroparesis [1,2] or with gastric outlet obstruction following esophagectomy [3]. In the current case, chronic scarring from the sulfuric acid made submucosal tunneling difficult and therefore direct pyloromyotomy was performed. The placement and maintenance of a covered stent in the correct position should be used for support during healing.

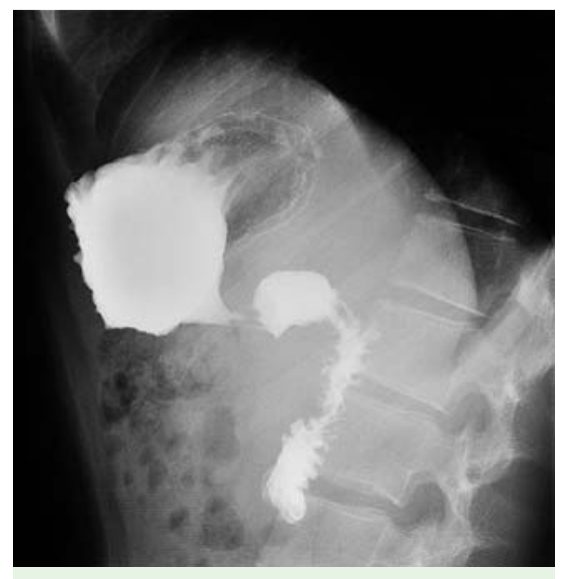

Fig. 4 Barium swallow at follow-up 3 months after repeat modified peroral pyloromyotomy and stent placement showed significant improvement in the passage of contrast.

Endoscopy_UCTN_Code_TTT_1AO_2AN

Competing interests: None

\section{References}

1 Khashab MA, Stein E, Clarke JO et al. Gastric peroral endoscopic myotomy for refractory gastroparesis: first human endoscopic pyloromyotomy (with video). Gastrointest Endosc 2013; 78: 764-768

2 Shlomovitz E, Pescarus R, Cassera MA et al. Early human experience with per-oral endoscopic pyloromyotomy (POP). Surg Endosc 2015; 2 : $543-551$

3 Chung H, Dallemagne B, Perretta S et al. Endoscopic pyloromyotomy for postesophagectomy gastric outlet obstruction. Endoscopy 2014; 46: E345 -E346

\section{Bibliography}

DOI http://dx.doi.org/

10.1055/s-0042-104279

Endoscopy 2016; 48: E119-E120

(c) Georg Thieme Verlag KG

Stuttgart · New York

ISSN 0013-726X

\section{Corresponding author}

\section{Yongjun Shi, MD}

Department of Digestive Internal Medicine Shandong Provincial Hospital Affiliated to Shandong University

9677 Jing 10 Road

Ji'nan 250000

\section{Mingyan Zhang', Dongxin $\mathbf{H u}^{2}$, Chunqing Zhang ${ }^{1}$, Yongjun Shi ${ }^{1}$}

${ }^{1}$ Department of Digestive Internal Medicine, Shandong Provincial Hospital Affiliated to Shandong University, Jinan, Shandong, China

${ }^{2}$ Department of Thoracic Surgery, Shandong Provincial Hospital Affiliated to Shandong University, Jinan, Shandong, China 